Brit. J. industr. Med., 1965, 22, 1.

\title{
MORTALITY OF GASWORKERS WITH SPECIAL REFERENCE TO CANCERS OF THE LUNG AND BLADDER, CHRONIC BRONCHITIS, AND PNEUMOCONIOSIS
}

\author{
BY \\ R. DOLL, R. E. W. FISHER, E. J. GAMMON, W. GUNN, G. O. HUGHES, \\ F. H. TYRER, and W. WILSON \\ From the Medical Research Council's Statistical Research Unit, University College Hospital Medical School, \\ London, and four Area Gas Boards
}

(RECEIVED FOR PUBLICATION NOVEMBER 4, 1964)

The mortality of selected groups of gasworkers has been observed over a period of eight years, and a comparison has been made of the mortality from different causes among different occupational groups. Men were included in the study if they had been employed by the industry for more than five years and were between 40 and 65 years of age when the observations began. All employees and pensioners of four area Gas Boards who met these conditions were initially included; but the number was subsequently reduced to 11,499 by excluding many of the occupations which did not involve entry into the carbonizing plants or involved this only irregularly. All but $0.4 \%$ of the men were followed successfully throughout the study. Mortality rates, standardized for age, were calculated for 10 diseases, or groups of diseases, for each of three broad occupational classes, i.e., those having heavy exposure in carbonizing plants (class A), intermittent exposure or exposure to conditions in other gas-producing plants (class B), and no such exposure (class C).

The results showed that the annual death rate was highest in class $A(17 \cdot 2$ per 1,000$)$, intermediate in class $B(14.6$ per 1,000$)$, and lowest in class $C(13.7$ per 1,000$)$, the corresponding mortality for all men in England and Wales over the same period being slightly lower than the rate for class $A$ $(16 \cdot 3$ per 1,000$)$. The differences between the three classes were largely accounted for by two diseases, cancer of the lung and bronchitis. For cancer of the lung the death rate $(3.06$ per 1,000$)$ ivas $69 \%$ higher in class $A$ than in class $C$; for bronchitis $(2.89$ per 1,000$)$ it was $126 \%$ higher. For both diseases the mortality in class $B$ was only slightly higher than in class $C$, and in both these categories the mortality was close to that observed in the country as a whole.

Three other causes of death showed higher death rates in the exposed classes than in the unexposed or in the country as a whole, but the numbers of deaths attributed to them were very small. The death rate from cancer of the bladder in class $A$ was four times that in class $C$, but the total number of deaths was only 14. Five deaths were attributed to pneumoconiosis, four of which occurred in bricklayers (class B). One death from cancer of the scrotum occurred in a retort house worker.

For other causes of death the mortality rates were similar to or lower than the corresponding national rates.

Examination of the data separately for each area Board showed that the excess mortality from lung cancer and chronic bronchitis in retort house workers persisted in each area. For two Boards the mortality from other causes was close to that recorded for other men living in the same region; in the other two Boards it was substantially lower.

A comparison between the mortality of men who worked in horizontal retort houses and of those who worked in vertical houses suggested that the risk of lung cancer was greater in the horizontal houses and the risk of bronchitis was greater in the vertical houses, the differences being, however, not statistically significant.

In the light of these and other data, it is concluded that exposure to products of coal carbonization can give rise to cancer of the lung and to bronchitis, and probably also to cancer of the bladder. A risk of pneumoconiosis from work on the repair and setting of retorts is confirmed. 
The occupational hazards of the gas industry have long been of special interest, not only because of the large number of men employed, but also because of their possible bearing on the health of the many people who are exposed to the products of coal carbonization in other situations. The first hazards to be recognized were cancer of the skin and cancer of the scrotum. For these cancers the incidence among the process workers was so large relative to that among the unexposed population, and the evidence from other industries and from laboratory research was so strong, that there was little hesitation in accepting that they were caused by contact with coal tar. As a result, preventive measures were undertaken and both these conditions have now been practically eliminated from the industry.

Subsequently attention was drawn to the possibility that there might also be risks of cancer of the bladder (Henry, Kennaway, and Kennaway, 1931) and of the lung (Kennaway and Kennaway, 1936 and 1947; Kuroda and Kawahata, 1936; Kuroda, 1937; and Kawahata, 1938).

For cancer of the lung, this has been confirmed by mortality studies in Britain (Doll, 1952), Canada (Sutherland, 1959) and the United States of America (Christian, 1962). The numbers of deaths have, however, been small and it is not possible from these data to say whether the risk is widespread in the industry or is limited to specific occupations within it. That some groups may be unaffected is suggested by Reid and Buck's (1956) finding that there was no excess mortality among men employed in the production of metallurgical coke. For cancer of the bladder, no other substantial evidence has yet been adduced.

The present study was undertaken at the request of the Ministry of Fuel and Power* with the special object of obtaining more information about the risk of lung cancer. In particular it was hoped to define the extent of the risk and the situations in which it is specially liable to occur. Since interest was concentrated on a disease which is nearly always fatal, the study was limited to the collection of mortality data. The results can therefore provide information only about occupational hazards which have a substantial fatality rate; they can provide none about other possible hazards, such as 'tar warts', which, when properly treated, are reflected only in morbidity statistics.

\section{Method}

Information was sought about men who at the beginning of the study (September 1, 1953) were employed by, or in receipt of a pension from, any one of

*Now the Ministry of Power. four area Boards. With the exception of one Board at which men employed in small works were excluded, all were included who were between 40 and 65 years of age and who had been employed by the industry for more than five years. For each employee a record was made of his name, address, place of employment, employment number, date of birth, and date of entering the industry, the number of years he had been employed in the industry, and his occupation at the beginning of the study.

Occupations were classified in 34 categories and grouped into four classes according to the extent to which the work involved exposure to the products of coal carbonization. The classes were:

A. Heavy exposure, i.e., coal carbonizing process workers;

B. Intermittent exposure, i.e., men whose work involved periodic entry into gas-producing plant, plus other process workers in gas-producing plant not included in class $\mathrm{A}$;

$$
\text { C. }\left\{\begin{array}{l}
\mathrm{C}_{1} \text { Exposure only to by-products, i.e., process } \\
\text { and maintenance workers in chemical and by- } \\
\text { products plant; } \\
\mathrm{C}_{2} \text { Minimal or no exposure, i.e., all other } \\
\text { employees. }
\end{array}\right.
$$

Altogether 26,856 men were studied, for each of whom follow-up information was sought annually. After three years, examination of the results showed that the objects of the study would not be achieved for several years. At the same time it was clear that there was unlikely to be any substantial risk of lung cancer among those men who were not working regularly in the carbonizing plants. The work was therefore reduced by limiting the study to men who were employed in selected occupations. All men in class $A$ (carbonizing plant workers) and class $C_{1}$ (by-products process and maintenance workers) were included; but men in class B were limited to those employed on maintenance work in gas-producing plant and to process workers in gas-producing plant other-than retort houses, and men in class $\mathrm{C}_{2}$ were limited to prepayment meter collectors, credit meter readers, and gas fitters. As a result the number of men studied was reduced to 11,499. These were followed for eight years, and the mortality rates among them were observed.

For each death, information about the cause was obtained from the death certificate, and the cause was classified according to the seventh revision of the international list of causes of death (World Health Organization, 1957). The corresponding populations were determined by working out the numbers of man-years lived in each five-year age group, men who were known to have died or emigrated being assumed to have been at risk for half the year in which they died or left the country. Death rates were obtained separately for each five-year age group, and the results were summarized for all ages by calculating standardized rates, taking the total numbers of man-years at risk for all occupations and all Gas Boards as the standard.

\section{Results}

Follow-up.-Table 1 shows the number of men 
TABLE 1

NUMBER OF MEN STUDIED AND NUMBER UNTRACED AFTER EIGHT YEARS, BY AREA BOARD AND OCCUPATIONAL CLASS

\begin{tabular}{|c|c|c|c|c|c|c|c|c|c|c|}
\hline \multirow{3}{*}{$\begin{array}{l}\text { Gas } \\
\text { Board }\end{array}$} & \multicolumn{8}{|c|}{ Number of Men in Occupational Class } & \multirow{2}{*}{\multicolumn{2}{|c|}{$\begin{array}{l}\text { Total Number } \\
\text { in All Classes }\end{array}$}} \\
\hline & \multicolumn{2}{|c|}{$A^{*}$} & \multicolumn{2}{|c|}{$\mathbf{B}^{*}$} & \multicolumn{2}{|c|}{$\mathrm{C}_{1}^{*}$} & \multicolumn{2}{|c|}{$\mathrm{C}_{2}^{*}$} & & \\
\hline & Studied & Untraced & Studied & Untraced & Studied & Untraced & Studied & Untraced & Studied & Untraced \\
\hline $\begin{array}{l}\text { I } \\
\text { II } \\
\text { III } \\
\text { IV }\end{array}$ & $\begin{array}{l}422 \\
545 \\
743 \\
739\end{array}$ & $\begin{array}{l}1(0.2) \dagger \\
3(0.6) \\
5(0.7) \\
3(0.4)\end{array}$ & $\begin{array}{r}431 \\
685 \\
1164 \\
1273\end{array}$ & $\begin{array}{l}3(0.7) \\
4(0.6) \\
3(0 \cdot 3) \\
6(0 \cdot 5)\end{array}$ & $\begin{array}{r}26 \\
18 \\
171 \\
364\end{array}$ & $\begin{array}{l}0(0.0) \\
0(0.0) \\
0(0.0) \\
3(0.8)\end{array}$ & $\begin{array}{r}506 \\
892 \\
1465 \\
2055\end{array}$ & $\begin{array}{l}3(0.6) \\
2(0.2) \\
6(0.4) \\
8(0.4)\end{array}$ & $\begin{array}{l}1385 \\
2140 \\
3543 \\
4431\end{array}$ & $\begin{array}{r}7(0.5) \\
9(0.4) \\
14(0.4) \\
20(0.5)\end{array}$ \\
\hline All Boards & 2449 & $12(0 \cdot 5)$ & 3553 & $16(0 \cdot 5)$ & 579 & $3(0.5)$ & 4918 & $19(0.4)$ & 11499 & $50(0.4)$ \\
\hline
\end{tabular}

*See text (page 2) for definition.

+ Percentage untraced in parentheses.

studied in each Board and in each occupational class and the number who were not traced at the end of the period of follow-up. These last were assumed to have survived so that the total mortality may have been slightly underestimated. Only 50 men $(0.4 \%$ of the total) were, however, untraced, and this defect is unlikely to have biased the results since the men were distributed evenly throughout all the principal groups. Even if they had died, which is extremely unlikely, the total death rate would have been increased by less than $4 \%$.

Mortality by Occupation.-Table 2 shows the numbers of deaths and the annual death rates, standardized for age, for all men in each occupational class, together with the corresponding death rate for England and Wales for the same period (1953-61). The highest death rate is found among the class $A$ workers $(17 \cdot 2$ per 1,000$)$ and the lowest among the 'unexposed' workers in classes $\mathrm{C}_{1}$ and $\mathrm{C}_{2}$ $(12.8$ and 13.8 per 1,000$)$. It is notable that the corresponding rate for England and Wales (16.4 per 1,000 ) is closer to the highest rate than to the lowest.
The numbers of deaths in the three largest classes are substantial and are sufficient to justify examining the principal causes of death separately. The number of deaths among by-products workers (58) is, however, too small for useful division. The mortality experience of this class, moreover, provides no evidence of any appreciable occupational hazard, so that here and in subsequent tables they have been combined with men in other occupations (class $\mathrm{C}_{2}$ ) to provide a single group of men without exposure in coal carbonizing plants (class C).

Examination of the individual causes of death shows a substantial difference between the different classes of occupation only in the case of lung cancer and bronchitis. For both conditions the highest mortality occurs in class A. In both these instances the death rate in class $\mathrm{A}$ is higher than the national rate $(+69 \%$ for cancer of the lung; $+112 \%$ for bronchitis), whereas the rates for classes $\mathrm{B}$ and $\mathrm{C}$ are close to it.

Three other causes of death show higher death rates in the exposed classes than in the unexposed or in the country as a whole. The numbers of deaths

TABLE 2

STANDARDIZED ANNUAL DEATH RATES PER 1,000 MEN, ALL BOARDS GROUPED TOGETHER AND ENGLAND AND WALES, 1953-61, BY CAUSE

\begin{tabular}{|c|c|c|c|c|c|c|c|c|}
\hline \multirow{3}{*}{ Cause of Death } & \multicolumn{8}{|c|}{ Death Rate } \\
\hline & \multicolumn{5}{|c|}{ Occupational Class } & \multirow{2}{*}{\multicolumn{2}{|c|}{ All Classes }} & \multirow{2}{*}{$\begin{array}{c}\text { England } \\
\text { and } \\
\text { Wales }\end{array}$} \\
\hline & $\mathbf{A}$ & B & $\mathrm{C}_{1}$ & $C_{2}$ & $C^{*}$ & & & \\
\hline $\begin{array}{l}\text { Cancer of lung } \\
\text { Cancer of bladder } \\
\text { Cancer of skin and scrotum } \\
\text { Other cancer } \\
\text { Bronchitis } \\
\text { Pneumoconiosis } \\
\text { Other respiratory diseases: } \\
\text { Arteriosclerotic and degenerative heart disease } \\
\text { Accidents and other violence } \\
\text { Other causes }\end{array}$ & $\begin{array}{l}3 \cdot 06 \\
0 \cdot 31 \\
0 \cdot 07 \\
1.96 \\
2 \cdot 89 \\
0 \cdot 05 \\
1 \cdot 19 \\
3 \cdot 34 \\
0 \cdot 76 \\
3 \cdot 59\end{array}$ & $\begin{array}{l}2 \cdot 04 \\
0 \cdot 20 \\
0 \cdot 00 \\
2 \cdot 20 \\
1 \cdot 34 \\
0 \cdot 13 \\
0 \cdot 88 \\
3 \cdot 53 \\
0 \cdot 63 \\
3 \cdot 70\end{array}$ & $\begin{array}{l}1.09 \\
0.00 \\
0.00 \\
1.77 \\
1.94 \\
0 \cdot 00 \\
0 \cdot 86 \\
3 \cdot 70 \\
0.72 \\
2 \cdot 69\end{array}$ & $\begin{array}{l}1.90 \\
0.09 \\
0.00 \\
2 \cdot 13 \\
1 \cdot 19 \\
0.00 \\
1.07 \\
3.68 \\
0.56 \\
3.21\end{array}$ & $\begin{array}{l}1.81 \\
0.08 \\
0.00 \\
2.09 \\
1.28 \\
0.00 \\
1.05 \\
3.68 \\
0.57 \\
3.14\end{array}$ & $\begin{array}{l}2.14 \\
0.16 \\
0.01 \\
2.11 \\
1.62 \\
0.06 \\
1.03 \\
3.55 \\
0.64 \\
3.41\end{array}$ & $\begin{array}{c}(187) \dagger \\
(14) \\
(1) \\
(184) \\
(141) \\
(5) \\
(90) \\
(310) \\
(56) \\
(298)\end{array}$ & $\begin{array}{c}1.81 \\
0.14 \\
0.02 \\
2.29 \\
1.36 \\
(0.07) \\
1.14 \\
4.48 \\
0.72 \\
4.31\end{array}$ \\
\hline All causes & $\begin{array}{l}17 \cdot 21 \\
(298) \dagger\end{array}$ & $\begin{array}{l}14 \cdot 64 \\
(428)\end{array}$ & $\begin{array}{c}12 \cdot 77 \\
(58)\end{array}$ & $\begin{array}{l}13.84 \\
(502)\end{array}$ & $\begin{array}{l}13 \cdot 70 \\
(560)\end{array}$ & $14 \cdot 73$ & $(1,286)$ & $\begin{array}{c}16.35 \\
-\end{array}$ \\
\hline
\end{tabular}

*Classes $\mathrm{C}_{1}$ and $\mathrm{C}_{2}$ combined.

$\dagger$ Number of deaths in parentheses.

†Including pulmonary tuberculosis. 
are, however, very small. Fourteen deaths were attributed to cancer of the bladder, and it is possibly of interest that the highest rate, based on only five cases, is recorded in class A. Only one death was attributed to cancer of the scrotum, and no death was attributed to cancer of the skin. Two other deaths from cancer of the scrotum are, however, known to have occurred among the Gas Board employees during the same period; they are not included in Table 2 because the men concerned were not included in the population under investigation. Two of the men had been retort house workers for 32 and 38 years respectively before the appearance of the growth. The third had been employed as a labourer in a tar distillation plant for $\mathbf{4 7}$ years. Five deaths were attributed to pneumoconiosis. One man had been an underground coal cutter before entering the gas industry in 1948; subsequently he was employed as a works yard labourer (one year), a retort house worker (four years), and a mains labourer (four years). Four men had been employed as bricklayers within the industry for periods of between 10 and 39 years. Altogether 198 men were classed as bricklayers (including retort setters) or as bricklayers' foremen at the beginning of the study, so that the mortality from pneumoconiosis among them was slightly more than $2 \%$ in the course of eight years. Pneumoconiosis, silicosis or pulmonary fibrosis without any indication of tuberculosis were referred to as contributory causes of death in 11 other instances. Four were in bricklayers and retort setters, five in retort house workers (one of whom had previously been employed as a coal miner in South Wales and one as a foundry worker), one in a retort house welder, and one in a meter reader. Details of the three cases of cancer of the scrotum and of the five deaths from pneumoconiosis are given in the Appendix (p. 11).

For other causes of death the differences between the classes are small and the mortality rates are similar to or (in the case of arteriosclerotic and degenerative heart disease and the group of other remaining causes) less than the corresponding national rates.

Mortality by Board. - Table 3 shows the individual results for each of the four Boards. Because of the small numbers of deaths figures are given separately only for cancer of the lung and bronchitis; all other possibly occupational causes have been grouped together (cancers of the bladder, skin, and scrotum and pneumoconiosis) as have all other causes of death. In this Table the mortality rates have been compared with the estimates of the corresponding regional rates rather than with the rates for the whole country. Since the majority of gasworkers live in large conurbations, the rates chosen for comparison have been the rates for the regional conurbations rather than for the regions as a whole. In general these rates are somewhat higher than the regional rates (certainly for cancer of the lung and bronchitis) so that in the absence of any occupational hazards, the rates for the various occupational classes might be expected to be slightly lower than the rates for the corresponding conurbations. For two of the Boards, situated in the South-Eastern region, the appropriate conurbation has been taken to be Greater London.

For cancer of the lung the mortality rates in the class A workers are, in each Board, higher than the rates for the corresponding conurbations, the excess varying from $9 \%$ to $74 \%$. Similar results are obtained for bronchitis, the excess in class A workers varying from $7 \%$ to $144 \%$. It may be noted, however, that the excess mortality from the two conditions does not appear to be correlated, the greatest excess from cancer of the lung being associated in one Board with the least excess from bronchitis.

The mortality from other 'non-occupational' causes shows no consistent difference between the occupational classes and is, in two of the Boards, similar in each class. In Board II the mortality is somewhat higher among class A and class B workers, and in Board IV it is higher in class C. For Boards I and II the mortality for all classes of worker combined is closely similar to the estimated regional rates; in Boards III and IV the combined mortality is substantially lower $(9.7$ and 9.0 respectively against an estimated 12.4 per 1,000 for each). As a result of this deficiency there is also, in these Boards, a deficiency of deaths from all causes in each of the occupational classes, most marked in classes B and C. The deficiency is slightly reduced if regional mortality rates are substituted for the Greater London rates (lung cancer $2 \cdot 10$, bronchitis $1 \cdot 22$, other 'non-occupational' causes $12 \cdot 21$, all causes 15.77 per 1,000 ), but it is still substantial.

Tests of Statistical Significance.-In view of these apparently anomalous results the best evidence of the existence of any occupational hazards is likely to be obtained from comparisons within the industry; that is, by comparing the observed number of deaths in each occupational class with the number expected from the experience of all the workers in each Board. For example, the annual death rate from lung cancer among men aged 55 to 60 in Board III was 3.305 per 1,000 . Class A workers employed by Board III provided 1,134 man-years at risk at these ages, so that the expected number of deaths from lung cancer was 3.305

$\overline{1,000} \times 1,134$ or $3 \cdot 75$. Similar calculations were 
TABLE 3

STANDARDIZED ANNUAL DEATH RATES PER 1,000 MEN AMONG EMPLOYEES OF DIFFERENT BOARDS COMPARED WITH THE RATES OBSERVED IN THE CORRESPONDING REGIONAL CONURBATIONS

\begin{tabular}{|c|c|c|c|c|c|c|}
\hline \multirow{3}{*}{ Gas Board } & \multirow{3}{*}{ Cause of Death } & \multicolumn{5}{|c|}{ Death Rate } \\
\hline & & \multicolumn{3}{|c|}{ Occupational Class } & \multirow{2}{*}{ All Classes } & \multirow{2}{*}{$\begin{array}{c}\text { Regional } \\
\text { Conurbation }\end{array}$} \\
\hline & & A & B & C & & \\
\hline \multirow[t]{2}{*}{ I } & $\begin{array}{l}\text { Cancer of lung } \\
\text { Bronchitis } \\
\text { Other 'occupational causes'* } \\
\text { Other causes }\end{array}$ & $\begin{array}{r}2 \cdot 94 \\
4 \cdot 54 \\
0 \cdot 90 \\
14 \cdot 52\end{array}$ & $\begin{array}{r}1 \cdot 22 \\
1 \cdot 47 \\
0 \cdot 22 \\
14 \cdot 55\end{array}$ & $\begin{array}{r}1 \cdot 88 \\
1 \cdot 14 \\
0.00 \\
13 \cdot 56\end{array}$ & $\begin{array}{r}2 \cdot 00(22) \dagger \\
2 \cdot 20(24) \\
0.38 \quad(4) \\
14 \cdot 15(155)\end{array}$ & $\begin{array}{c}2 \cdot 20 \\
2 \cdot 24 \\
0 \cdot 24 \ddagger \\
14 \cdot 95\end{array}$ \\
\hline & All causes & $\begin{array}{l}22.90 \\
(70) \dagger\end{array}$ & $\begin{array}{c}17 \cdot 46 \\
(65)\end{array}$ & $\begin{array}{c}16 \cdot 57 \\
(70)\end{array}$ & $18 \cdot 73$ & $19 \cdot 63$ \\
\hline \multirow[t]{2}{*}{ II } & $\begin{array}{l}\text { Cancer of lung } \\
\text { Bronchitis } \\
\text { Other 'occupational causes' } \\
\text { Other causes }\end{array}$ & $\begin{array}{r}2 \cdot 38 \\
2 \cdot 75 \\
0 \cdot 82 \\
14 \cdot 62\end{array}$ & $\begin{array}{r}2 \cdot 45 \\
1 \cdot 70 \\
0 \cdot 33 \\
15 \cdot 06\end{array}$ & $\begin{array}{r}1 \cdot 31 \\
1.66 \\
0 \cdot 00 \\
12 \cdot 23\end{array}$ & $\begin{array}{rr}1.97 & (32) \\
1.94 & (32) \\
0.30 & (5) \\
13.74 & (224)\end{array}$ & $\begin{array}{c}2 \cdot 19 \\
1 \cdot 93 \\
0 \cdot 24 \ddagger \\
13 \cdot 65\end{array}$ \\
\hline & All causes & $\begin{array}{r}20 \cdot 57 \\
(83)\end{array}$ & $\begin{array}{r}19 \cdot 54 \\
(108)\end{array}$ & $\begin{array}{r}15 \cdot 20 \\
(102)\end{array}$ & 17.95 & $18 \cdot 01$ \\
\hline \multirow[t]{2}{*}{ III } & $\begin{array}{l}\text { Cancer of lung } \\
\text { Bronchitis } \\
\text { Other 'occupational causes' } \\
\text { Other causes }\end{array}$ & $\begin{array}{l}3 \cdot 86 \\
1 \cdot 45 \\
0 \cdot 24 \\
9 \cdot 49\end{array}$ & $\begin{array}{l}2 \cdot 40 \\
1 \cdot 27 \\
0 \cdot 62 \\
9 \cdot 50\end{array}$ & $\begin{array}{l}2 \cdot 20 \\
0 \cdot 75 \\
0 \cdot 00 \\
9 \cdot 78\end{array}$ & $\begin{array}{l}2.56 \quad(67) \\
1.08 \quad(29) \\
0.27 \quad(7) \\
9.68(258)\end{array}$ & $\begin{array}{c}2 \cdot 22 \\
1 \cdot 35 \\
0 \cdot 24^{\ddagger} \\
12 \cdot 41^{+}\end{array}$ \\
\hline & All causes & $\begin{array}{c}15 \cdot 05 \\
(74)\end{array}$ & $\begin{array}{l}13 \cdot 78 \\
(135)\end{array}$ & $\begin{array}{l}12 \cdot 72 \\
(152)\end{array}$ & $13 \cdot 59$ & $16 \cdot 22$ \\
\hline \multirow[t]{2}{*}{ IV } & $\begin{array}{l}\text { Cancer of lung } \\
\text { Bronchitis } \\
\text { Other 'occupational causes' } \\
\text { Other causes }\end{array}$ & $\begin{array}{l}2 \cdot 90 \\
3 \cdot 29 \\
0 \cdot 00 \\
7 \cdot 24\end{array}$ & $\begin{array}{l}1 \cdot 76 \\
1 \cdot 15 \\
0 \cdot 10 \\
8 \cdot 70\end{array}$ & $\begin{array}{l}1.78 \\
1.53 \\
0.16 \\
9.72\end{array}$ & $\begin{array}{lr}1.96 & (66) \\
1.69 & (56) \\
0.12 & (4) \\
9.02 & (301)\end{array}$ & $\begin{array}{c}2 \cdot 22 \\
1 \cdot 35 \\
0 \cdot 24_{\ddagger}^{\ddagger} \\
12 \cdot 41\end{array}$ \\
\hline & All causes & $\begin{array}{c}13.42 \\
(71)\end{array}$ & $\begin{array}{l}11 \cdot 71 \\
(120)\end{array}$ & $\begin{array}{l}13 \cdot 19 \\
(236)\end{array}$ & $12 \cdot 78$ & $16 \cdot 22$ \\
\hline
\end{tabular}

* Cancers of the bladder, scrotum, and skin, and pneumoconiosis.

+ Numbers of deaths in parentheses.

†In the absence of data for the regional distribution of these diseases the regional death rate has been assumed to be the same as for the whole country.

TABLE 4

NUMBERS OF DEATHS FROM DIFFERENT CAUSES IN EACH OCCUPATIONAL CLASS AND NUMBERS EXPECTED FROM THE EXPERIENCE OF ALL GASWORKERS, ALLOWING FOR AGE AND EMPLOYING BOARD

\begin{tabular}{|c|c|c|c|c|c|c|c|c|}
\hline \multirow{3}{*}{ Cause of Death } & \multicolumn{6}{|c|}{ Number of Deaths in Occupational Class } & \multirow{3}{*}{$\begin{array}{c}\chi^{2} \\
\text { for } \\
\text { Trend }\end{array}$} & \multirow{3}{*}{$\begin{array}{c}\text { Probability } \\
\text { of Trend } \\
\text { arising } \\
\text { due to } \\
\text { Chance }\end{array}$} \\
\hline & \multicolumn{2}{|c|}{$\mathbf{A}$} & \multicolumn{2}{|c|}{ B } & \multicolumn{2}{|c|}{ C } & & \\
\hline & Observed & Expected & Observed & Expected & Observed & Expected & & \\
\hline $\begin{array}{l}\text { Cancer of lung } \\
\text { Cancer of bladder } \\
\text { Bronchitis } \\
\text { Other 'occupational causes'* } \\
\text { Other cancer } \\
\text { Other respiratory diseases } \\
\text { Accidents and other violence } \\
\text { Other causes }\end{array}$ & $\begin{array}{r}54 \\
5 \\
49 \\
2 \\
35 \\
21 \\
14 \\
118\end{array}$ & $\begin{array}{r}37 \cdot 27 \\
2 \cdot 94 \\
28 \cdot 54 \\
1 \cdot 36 \\
38 \cdot 54 \\
19 \cdot 24 \\
12 \cdot 65 \\
123 \cdot 18\end{array}$ & $\begin{array}{r}59 \\
6 \\
40 \\
4 \\
64 \\
26 \\
18 \\
211\end{array}$ & $\begin{array}{r}62 \cdot 70 \\
4 \cdot 81 \\
47 \cdot 33 \\
2 \cdot 16 \\
62 \cdot 12 \\
30 \cdot 51 \\
17 \cdot 85 \\
203 \cdot 55\end{array}$ & $\begin{array}{r}74 \\
3 \\
52 \\
0 \\
85 \\
43 \\
24 \\
279\end{array}$ & $\begin{array}{r}87 \cdot 03 \\
6 \cdot 25 \\
65 \cdot 13 \\
2 \cdot 49 \\
83 \cdot 33 \\
40 \cdot 25 \\
25 \cdot 51 \\
281 \cdot 26\end{array}$ & $\begin{array}{r}8 \cdot 11 \\
3 \cdot 42 \\
13 \cdot 71 \\
-\overline{0 \cdot 25} \\
0 \cdot 02 \\
0 \cdot 24 \\
0 \cdot 02\end{array}$ & $\begin{array}{c}<0.01 \\
0.06 \\
<0.001 \\
\frac{t}{+} \\
\quad t \\
+\end{array}$ \\
\hline All causes & 298 & $263 \cdot 72$ & 428 & 431.03 & 560 & $591 \cdot 25$ & 5.68 & 0.02 \\
\hline
\end{tabular}

*Cancers of the scrotum and skin and pneumoconiosis.

$+0.1<P<0.9$.

made for all age groups and all Boards and the results were summed.

The results are shown in Table 4 for eight causes of death (or groups of causes). The significance of the differences has been assessed on the assumption that any unusual incidence would be most likely to occur among class A workers, with class B workers occupying a position intermediate between classes A and $C$. The value of $\chi^{2}$ has therefore been calculated for the trend in the ratio between the observed and expected numbers of deaths from class $A$ through class B to class C (Mantel, 1963, equation 13). In making this calculation, allowance has been made for the fact that the expected number has been derived from separate calculations for each age group and for each Board. Statistically significant trends are shown for cancer of the lung $(P<0.01)$ and for bronchitis $(P<0.001)$ and, despite the very small 
TABLE 5

NUMBERS OF DEATHS IN EACH OCCUPATIONAL CLASS AND NUMBERS EXPECTED FROM THE EXPERIENCE OF MEN LIVING IN CONURBATIONS, ALLOWING FOR AGE AND REGION

\begin{tabular}{|c|c|c|c|c|c|c|}
\hline \multirow{3}{*}{ Cause of Death } & \multicolumn{6}{|c|}{ Number of Deaths in Occupational Class } \\
\hline & \multicolumn{2}{|c|}{$\mathbf{A}$} & \multicolumn{2}{|c|}{$\mathbf{B}$} & \multicolumn{2}{|c|}{ C } \\
\hline & Observed & Expected & Observed & Expected & Observed & Expected \\
\hline $\begin{array}{l}\text { Cancer of lung } \\
\text { Bronchitis }\end{array}$ & $\begin{array}{l}54^{*} \\
49 \ddagger\end{array}$ & $\begin{array}{l}38.99 \\
27.98\end{array}$ & $\begin{array}{l}59 \\
40\end{array}$ & $\begin{array}{l}64 \cdot 03 \\
46 \cdot 74\end{array}$ & $\begin{array}{l}74 \\
52\end{array}$ & $\begin{array}{l}90 \cdot 18 \\
62 \cdot 30\end{array}$ \\
\hline All causes & 298 & $299 \cdot 74$ & $428+\S$ & $494 \cdot 68$ & $560 \div \S$ & $688 \cdot 34$ \\
\hline
\end{tabular}

${ }^{*} \mathbf{P}=0.02$

$+P<0.01$.

$\pm \mathbf{P}<0.001$.

$\S$ See text (page 10).

numbers, the trend for cancer of the bladder verges on significance $(P=0.06)$. No test was made for other possible occupational causes, partly because of the smallness of the numbers and partly because the trend test would be inappropriate for pneumoconiosis, the hazard being confined to class B. None of the other four groups of causes of death show any material relationship to work in coal carbonizing plants.

That the death rates from cancer of the lung and from bronchitis are increased among exposed workers is confirmed in Table 5, where the observed deaths have been compared with the numbers expected at the rates concurrently experienced in the corresponding regional conurbations. For both diseases the numbers of deaths are significantly increased among class A workers, but they do not differ significantly from the expected number in either of the other two classes. Since the mortality from lung cancer and from bronchitis is higher in conurbations than in the surrounding regions, and since some class A workers live outside the conurbations, the real excess among these workers must be greater than appears in the Table.

Mortality by Type of Retort House.-The conditions that give rise to an increased mortality from these diseases have been examined further by dividing the class A workers into three categories, according to the type of retort house in which they were working at the beginning of the study (September 1, 1953). Works in which only horizontal retorts had been used during the previous 10 years were classed as horizontal; works in which only vertical retorts had been used (including both intermittent and continuous types) were classed as vertical; all others were classed as mixed, including in this category houses which contained both horizontal and vertical retorts and those which were wholly vertical but had contained active horizontal retorts during the previous 10 years.
Comparison between the categories is complicated by the fact that the three types of retort house were not evenly distributed throughout the four Boards. One Board contained no horizontal houses and another contained very few vertical* houses. We could not therefore make a direct estimate of the numbers of deaths which would have been expected in each category if the type of retort house was immaterial and at the same time make allowance for regional differences in mortality. Regional differences are, however, important (Table 3) and must be taken into account, so that we had to estimate the expected numbers by an indirect method.

First, we used the death rates of the other gasworkers (classes B and C) to estimate, for each age and for each Board, the number of deaths that would have been expected among each type of class $A$ worker if they had not been exposed to any special hazard. The results summed for all ages and all Boards are shown in Table 6. Secondly, the expected numbers were scaled up to make the total deaths from each cause among all class A workers equal to the number actually observed. The results are shown in Table 7.

From these results, the mortality from lung cancer and from bronchitis would both appear to be increased among all three types of worker (Table 6). For lung cancer the increase is most marked among men who had worked with horizontal retorts, whereas for bronchitis the increase is most marked among men who had worked with vertical retorts. The numbers of deaths from each cause in each group of workers is, however, small, and the differences are not statistically significant (Table 7).

Smoking Habits.-The differences between the mortality experience of the various occupational groups are not apparently due to differences in

*The Board without horizontal retort houses did in fact contain works of this type, but they were small and scattered and the men employed in them had not been included in the study. 
TABLE 6

NUMBERS OF DEATHS AMONG MEN EMPLOYED IN DIFFERENT TYPES OF RETORT HOUSE AND NUMBERS EXPECTED FROM THE EXPERIENCE OF OTHER GASWORKERS, ALLOWING FOR AGE AND EMPLOYING BOARD

\begin{tabular}{|c|c|c|c|c|c|c|c|c|}
\hline \multirow{3}{*}{ Cause of Death } & \multicolumn{6}{|c|}{ Number of Deaths among Class A Workers Employed in } & \multirow{2}{*}{\multicolumn{2}{|c|}{$\begin{array}{c}\text { Total No. of } \\
\text { Deaths among } \\
\text { Class A Workers }\end{array}$}} \\
\hline & \multicolumn{2}{|c|}{ Horizontal Houses } & \multicolumn{2}{|c|}{ Mixed Houses } & \multicolumn{2}{|c|}{ Vertical Houses } & & \\
\hline & Observed & Expected & Observed & Expected & Observed & Expected & Observed & Expected \\
\hline $\begin{array}{l}\text { Cancer of lung } \\
\text { Cancer of bladder } \\
\text { Bronchitis } \\
\text { Other causes }\end{array}$ & $\begin{array}{r}14 \\
0 \\
6 \\
27\end{array}$ & $\begin{array}{r}7 \cdot 67 \\
0 \cdot 51 \\
3 \cdot 79 \\
35 \cdot 78\end{array}$ & $\begin{array}{r}28 \\
4 \\
22 \\
87\end{array}$ & $\begin{array}{r}15 \cdot 59 \\
1.08 \\
10 \cdot 83 \\
91 \cdot 61\end{array}$ & $\begin{array}{r}12 \\
1 \\
21 \\
76\end{array}$ & $\begin{array}{r}9.42 \\
0.56 \\
7.92 \\
67.65\end{array}$ & $\begin{array}{r}54 \\
5 \\
49 \\
190\end{array}$ & $\begin{array}{r}32.68 \\
2 \cdot 15 \\
22.54 \\
195.05\end{array}$ \\
\hline All causes & 47 & $47 \cdot 75$ & 141 & $119 \cdot 11$ & 110 & $85 \cdot 55$ & 298 & $252 \cdot 42$ \\
\hline
\end{tabular}

TABLE 7

NUMBERS OF DEATHS AMONG MEN EMPLOYED IN DIFFERENT TYPES OF RETORT HOUSE AND NUMBERS EXPECTED IF THE TYPE OF RETORT HOUSE WAS IMMATERIAL

\begin{tabular}{|c|c|c|c|c|c|c|c|c|}
\hline \multirow{3}{*}{ Cause of Death } & \multicolumn{6}{|c|}{ Number of Deaths among Class A Workers Employed in } & \multirow{3}{*}{$\begin{array}{c}\chi^{2} \\
\text { for } \\
\text { Trend }\end{array}$} & \multirow{3}{*}{$\begin{array}{l}\text { Probability } \\
\text { of Trend } \\
\text { arising } \\
\text { due to } \\
\text { Chance }\end{array}$} \\
\hline & \multicolumn{2}{|c|}{ Horizontal Houses } & \multicolumn{2}{|c|}{ Mixed Houses } & \multicolumn{2}{|c|}{ Vertical Houses } & & \\
\hline & Observed & Expected & Observed & Expected & Observed & Expected & & \\
\hline $\begin{array}{l}\text { Cancer of lung } \\
\text { Bronchitis }\end{array}$ & $\begin{array}{r}14 \\
6\end{array}$ & $\begin{array}{r}12 \cdot 67 \\
8 \cdot 24\end{array}$ & $\begin{array}{l}28 \\
22\end{array}$ & $\begin{array}{l}25 \cdot 76 \\
23 \cdot 54\end{array}$ & $\begin{array}{l}12 \\
21\end{array}$ & $\begin{array}{l}15 \cdot 57 \\
17 \cdot 22\end{array}$ & $\begin{array}{l}0.86 \\
1.52\end{array}$ & $\begin{array}{l}0.1<\mathbf{P}<0.9 \\
0.1<\mathrm{P}<0.9\end{array}$ \\
\hline All causes & 47 & $56 \cdot 37$ & 141 & $140 \cdot 62$ & 110 & $101 \cdot 00$ & $2 \cdot 24$ & $0.1<P<0.9$ \\
\hline
\end{tabular}

TABLE 8

SMOKING HABITS OF GASWORKERS

\begin{tabular}{|c|c|c|c|c|c|c|c|}
\hline \multirow{3}{*}{$\begin{array}{l}\text { Population } \\
\text { (no. of men) }\end{array}$} & \multirow{3}{*}{$\begin{array}{c}\text { Non- } \\
\text { smokers } \\
(\%)\end{array}$} & \multirow{3}{*}{$\underset{\substack{\text { Ex- } \\
\text { smokers }}}{ }$} & \multicolumn{5}{|c|}{ Continuing Smokers ( $\%)$} \\
\hline & & & \multirow[t]{2}{*}{ Pipe } & \multirow[t]{2}{*}{ Mixed } & \multicolumn{3}{|c|}{ Cigarette, smoking daily } \\
\hline & & & & & $1-9$ & $10-19$ & 20 or more \\
\hline $\begin{array}{l}\text { Retort house workers* }(214) \\
\text { Other gasworkers }(842)\end{array}$ & $\begin{array}{l}8 \cdot 3 \\
5 \cdot 8\end{array}$ & $\begin{array}{l}10 \cdot 2 \\
15 \cdot 3\end{array}$ & $\begin{array}{l}6.7 \\
5 \cdot 9\end{array}$ & $\begin{array}{l}4 \cdot 4 \\
6 \cdot 2\end{array}$ & $\begin{array}{l}18 \cdot 1 \\
17 \cdot 8\end{array}$ & $\begin{array}{l}38 \cdot 5 \\
35 \cdot 5\end{array}$ & $\begin{array}{l}13.9 \\
13 \cdot 4\end{array}$ \\
\hline $\begin{array}{l}\text { All gasworkers, aged } 40-64 \text { years }(1,033) \\
\text { England and Wales, men aged } 35-59 \text { years, } 1956 \dagger\end{array}$ & \multicolumn{2}{|c|}{$\begin{array}{l}20 \cdot 6 \\
21 \cdot 4\end{array}$} & $\begin{array}{l}6.0 \\
7.6\end{array}$ & $\begin{array}{r}5 \cdot 6 \\
10 \cdot 0\end{array}$ & \multicolumn{3}{|c|}{$\begin{array}{l}67 \cdot 8 \\
61 \cdot 1\end{array}$} \\
\hline
\end{tabular}

*Smoking habits standardized for age, using the age distribution of the 'other gasworkers' as standard.

+Todd (1957).

smoking habits. A $10 \%$ sample of all the workers included in the study who were available one year after the start of the study was selected at random, and information about their smoking habits was obtained from personal interviews with a single investigator.* The results, summarized in Table 8, show that the retort house workers did not smoke any more than other workers and all had much the same smoking habits as other men throughout the country. The possibility of there being more subtle differences as, for example, in the frequency of relighting cigarettes, was examined.

\section{Discussion}

It is clear from these observations that the mortality of gasworkers varied appreciably with the type of work. The mortality was highest among men

*Miss Keena Jones of the Medical Research Council's Statistical Research Unit. who had regular contact with the process of coal carbonization. Among them the death rate was $26 \%$ more than among men who worked in the streets or in customers' houses; men who had an intermediate type of contact had an intermediate death rate. These differences could be almost wholly accounted for by two common diseases, cancer of the lung and bronchitis, and by three rare ones, cancer of the bladder, cancer of the scrotum, and pneumoconiosis. For these diseases, for all of which there is independent evidence to justify relating them to occupational hazards of the industry, the total annual death rate was 6.4 per 1,000 among men in regular contact with the process, $3 \cdot 7$ per 1,000 in the intermediate group, and $3 \cdot 2$ per 1,000 in the group without contact. For all other diseases combined, the death rates in the three groups were within $4 \%$ of one another $(10 \cdot 8,10 \cdot 9$, and $10 \cdot 5$ per 1,000 respectively).

Cancer of the scrotum is already scheduled as an industrial disease when it occurs among men exposed 
to coal tar and it will not be considered in detail. On many occasions in the past the disease is known to have had a long induction period (Henry, 1946), and the occurrence of three deaths (only one of which was in the population under direct observation) may be attributable to conditions which are no longer characteristic of the industry. It indicates, however, that there is still a need for vigilance.

In view of the large amounts of carcinogens that may be found in the air of retort houses (Lawther, Commins, and Waller, 1965), it is not surprising that retort house workers should experience a special risk of lung cancer. Past evidence from this country has indicated that a risk is likely to exist, but the hazard has not apparently been very great. Kennaway and Kennaway (1936 and 1947) examined the occupations of men certified as having died of lung cancer between 1921 and 1938. Of the five occupations with the highest estimated mortality, four involved exposure to the fumes associated with coal carbonization (labourers at 'patent fuel' works, gas stokers and coke oven chargers, gas-producer men, and gasworks foremen and inspectors). Among men employed in these occupations the expected number of deaths was 51 and the observed number 125, a ratio of two and a half to one. A slightly lower ratio was found some years later in a study of 2,071 pensioners of a large London gas company, 25 deaths being observed against 14 expected at the rates recorded for male Londoners of the same ages (Doll, 1952). All types of manual occupations were, however, covered by this study, including many which did not involve direct contact with the process of manufacture. Later still the Registrar General (1958) found that the standardized mortality ratio for 'makers of coal gas and coke' had been reduced to 129, 63 deaths occurring in the period 1949 to 1953 at ages 20 to 64 years against 49 expected, and at this period, 29 of the 110 main occupational groups examined had higher ratios.* The figures for gasworkers, however, may have been diluted by the inclusion of coke oven workers within the same category. There are differences between coking plants and gasworks in this country-in the construction of the plant, the method of treatment of the coal, and sometimes in the type of coal usedand it is notable that Reid and Buck (1956) failed to find any evidence of an increased risk among men who work in the former industry.

Positive evidence has been reported from four other countries. In Japan 12 of 15 cancer deaths in 500 gas-generator workers were due to lung cancer. Lung cancer was a rare disease in Japan, and at the

*For 26 of the groups the ratios lay between 130 and 177; the remaining three groups with higher ratios all referred to retired Servicemen, and the populations at risk are likely to have been biased. time of the study, no such cases were recorded among 49 cancer deaths occurring in 19,000 other employees of the same factory (Kuroda and Kawahata, 1936; Kuroda, 1937). In Canada, Sutherland (1959) investigated 19 deaths among men who worked in horizontal retort houses and found that nine were attributed to respiratory cancer, whereas the expected number based on the experience of the general population was less than one. No such excess was found among the employees who had not worked in the retort house, nor was there any excess among employees at another works where more modern retorts were used. In Norway, Bruusgaard (1959) studied the cause of death of 125 gasworkers who died while employed by or pensioned from a large gasworks in a 15-year period. Of these deaths, 41 were due to cancer, including 12 which Bruusgaard classified as attributable to 'tumours of the respiratory tract' (including in this category five deaths from lung cancer, two from laryngeal cancer, and five from cancer of the nasal sinuses and pharynx). Respiratory cancer was rare in Norway at that period, and it accounted for only $9 \%$ of cancer deaths and $1.5 \%$ of all deaths among Norwegian men over 40 years of age. In the U.S.A., Christian (1962) studied the mortality of men employed by a 'public power plant' and found that the highest mortality from lung cancer occurred in a small group of 104 coke oven workers. In this group the annual death rate from lung cancer was 7.8 per 1,000 against 0.8 per 1,000 for other gas plant workers and 0.5 per 1,000 for all other employees. In another study of over 6,000 men employed in coke and coal tar plants for over five years and followed for between seven and 17 years (Phair, personal communication), the total death rate was found to be considerably less than the national average, presumably because of selective enrolment of fit men, but there was a substantially increased mortality from lung cancer among nonwhite workers, 16 deaths being recorded against 3.5 expected. The excess was not spread out evenly over the industry but was concentrated in a group of plants situated in a single country.

The present data ccnfirm the existence of a risk among retort house workers and are compatible with a very slight risk among men who work in other gas-producing plants or who enter gas-producing plants irregularly. Among retort house workers, the risk did not appear to be high when measured in relation to that in the general population (of the order of $150 \%$ ) but the 'normal' risk is now so great that even this small excess resulted in the disease being responsible for $18 \%$ of all deaths (54 out of 298). Whether the risk is limited to the conditions of work in old horizontal retort houses cannot be determined from these observations. The mortality 
was higher among men who worked in such houses, among whom it accounted for $30 \%$ of all deaths (14 out of 47), but the mortality was also raised among men who worked with vertical retorts, and the difference between the two sets of observations was not statistically significant. If, as seems probable, the disease is due to the presence of carcinogenic polycyclic hydrocarbons in the air, it would not be surprising if horizontal houses carried a higher risk; but chemical observations provide no reason to suppose that it should be entirely absent from the vertical houses (Lawther et al., 1965). More data are needed to show how far the risk among horizontal retort house workers can be accounted for by the experience of men who have worked in the most polluted areas, i.e., topmen, and to determine the extent of the risk in vertical houses.

Whether the industrial factors act synergistically with those responsible for non-industrial cases, or whether they act independently so that the risks are added, cannot be determined from the present data. Information about the smoking habits of individual gasworkers showed that the industrial risk could not be attributed to differences in the amount smoked, but the numbers of cases were too small to throw any light on the way in which the industrial factor and cigarette smoking might interact.

Very little new evidence has been obtained to implicate cancer of the bladder as a specific hazard of the gas industry since Henry et al. (1931) examined the occupations recorded on death certificates. Between 1921 and 1928, 5,621 men died of cancer of the bladder in England and Wales, 59 of whom were described as gasworkers or in similar employment. Henry et al. divided them into 10 occupational groups and found that the mortality was above the national average in nine. In six, patent fuel labourers, gasworks engine and crane drivers, tar distillery workers, gasworks managers, gas fitters, and gas stokers, the excess was more than $50 \%$ above average. The only other information is Bruusgaard's (1959) series which revealed five deaths from bladder cancer in a total of 125 deaths among Norwegian gasworkers. In the present data the proportion of bladder cancer deaths is small, $1.1 \%$ in a total of 1,286 deaths, but the mortality rate is four times higher among men who were regularly exposed to the process than among the unexposed $(0.31$ and 0.08 per 1,000 respectively) and the increase in rate with increase in the amount of exposure is not very likely to be due to chance $(\mathrm{P}=0.06)$.

By themselves these observations would not provide convincing evidence of any special hazard. It must, however, be noted that Somerville (personal communication) detected $\beta$-naphthylamine in the fumes inside a retort house, and, in the absence of any contrary evidence, it would seem reasonable to assume that the reported small excess is due to the conditions of work.

Pneumoconiosis has been reported to occur among two groups of employees in the gas industry. Cummins, Dunn, Rayner, and Sullivan (1952) found five cases in 625 Australian gasworkers, three in men who had worked as bricklayers for 14 or more years, and Tyrer, Gregory, and Carson (1953) found three cases in coke screen attendants. No information has been obtained about the latter occupation in our study, but it is notable that four of the five pneumoconiosis deaths occurred in bricklayers, who formed less than $2 \%$ of the total population. None of these four men had been employed in a dusty occupation before entering the industry. Bricklayers, however, may be exposed to large quantities of siliceous dust, if their work entails the repair and resetting of retorts, and it is not surprising if, under these conditions, they run a risk of developing pneumoconiosis.

According to the most recent of the Registrar General's analyses of occupational mortality (Registrar General, 1958), the bronchitis mortality of men engaged in making coal gas and coke is below the national average, the standardized mortality ratio for 1949-53 (based on only 29 deaths) being 73.* No other reports have concerned themselves with this disease among gasworkers, and bronchitis has not generally been regarded as an occupational disease of the industry. This lack of attention is surprising since gasworkers are exposed to high concentrations of substances that contribute to the pollution of town air, and atmospheric pollution is widely believed to be an important cause of chronic bronchitis (e.g., Pemberton and Goldberg, 1954; Fairbairn and Reid, 1958; Daly, 1959; and Stocks, 1959). It is clear, however, from these and other reports that several other factors also contribute to bronchitis mortality. Social class differences, whatever they may be, account for a difference of 5 to 1 in the mortality among unskilled workers compared with men in the professional and executive class and a difference of 4 to 1 among their wives (Registrar General, 1958). Smoking habits may, in some circumstances, account for differences of 20 to 1 (Doll and Hill, 1964), and the effect of climate also has to be considered.

None of these factors provides a ready explanation of our observations. The total number of deaths from bronchitis is substantial (141) and it is hardly reasonable to attribute the differences between the

*For this purpose the Registrar General classes together all types of bronchitis (International List numbers 500-502) and we have followed his practice. Our figures can, however, be regarded as referring essentially to chronic bronchitis as this accounted for $93 \%$
of the deaths and was a contributory cause in two of the other 10 of the
cases. 
men in the different types of occupation to chance alone. Even when comparisons were made with men living in the big conurbations, the excess bronchitis mortality in retort house workers was so great that it could have been expected to occur by chance less than once in 1,000 times. In the Registrar General's data the experience of gasworkers was diluted by the inclusion of coke oven workers (see p. 9) and the small number of deaths reported in these occupations (29) is subject to a large random error. The negative national evidence does not therefore outweigh the evidence from the present study, and we conclude, as a working hypothesis, that the excess bronchitis mortality observed among the retort house workers was occupational in origin and related to the presence of dust and of the products of coal combustion in the air of the houses. Clearly, however, the hypothesis needs to be tested by further observations; in particular it is not clear why the mortality should appear to be higher in the vertical retort houses than in the horizontal, which is contrary to the experience with cancer of the lung. Lawther et al. (1965) certainly did not find any evidence of greater pollution in vertical houses than in horizontal; if anything it was the other way round, but the relevant substances may not have been examined. Alternatively, work in horizontal houses is generally heavier than in vertical houses, and the conditions in horizontal houses may have been so unfavourable for men with a tendency to bronchitis that they left the industry of their own accord before completing the five years' service necessary to have qualified for inclusion in the study. The numbers of deaths among men working in the different types of retort house are, however, small, and the observed differences between them may be due to chance.

The reason for the low mortality from all other 'non-occupational' diseases is also unexplained. It is not due to a beneficial effect of heavy physical work in retort houses, since it is observed among all types of employee (Tables 2 and 3); nor is it an attribute of the industry as a whole, since it is observed among the employees of only two of the four Boards (Table 3). One explanation might be that the mortality in two of the Boards was underestimated as a result of recording some men as alive who were in fact dead. A check on a randomly selected $10 \%$ sample at Board III failed, however, to indicate that any substantial number of deaths could have been missed. The status of all but one of the men was confirmed; this man was said to have been still employed by the Board, whereas he had actually left though he was still alive. If the explanation is that some deaths have been missed, the mortality from occupational diseases is presumably also underestimated.
An alternative explanation is that some selective bias resulted in the inclusion of a relatively healthy group of employees in two of the Boards. Work in horizontal retort houses is heavy, and it would be understandable if chronic invalids failed to qualify for inclusion in the study by continuing to work for five years. It is, however, difficult to see why such a bias should affect men employed as meter collectors, meter readers or gas fitters (class $\mathrm{C}$ ). The high rate of employment in the south east may perhaps have resulted in a more rapid labour turnover among unhealthy men, but if this were the explanation we should have anticipated that the bias would have worn off after the first few years of follow-up. In fact the mortality from non-occupational causes was practically the same in the first three and in the last five years of the study (Board III, 9.6 and 9.4 per 1,000; Board IV, 8.2 and 9.1 per 1,000 respectively).

Whatever the explanation, it is difficult to see how the deficiency could have produced a spuriously high mortality from occupational diseases, which, it may be noted, was raised in all four Boards. It is not, we think, reasonable to suggest that the deficiency of deaths from non-occupational causes is due to bias in favour of diagnosing cancer of the lung or bronchitis. First, the deficiency is apparent in all three occupational classes, whereas the excess mortality from lung cancer and from bronchitis is present only among class A workers. Secondly, the causes of death have been classified according to the information given on death certificates; these were completed by many different doctors who were unaware of the existence of the present study and not likely to be biased by knowledge of the subjects' occupation.

\section{Conclusion}

Mortality rates among retort house workers are higher than among other employees of the gas industry. This is largely due to an increased risk of dying from cancer of the lung or chronic bronchitis. The increase in risk is not large compared with the 'normal' risk in employees who were not exposed in retort houses $(69 \%$ for lung cancer and $126 \%$ for bronchitis); both these diseases are, however, common, and the excess mortality among retort house workers that was attributed to them amounted to $17 \%$ of the total death rate.

In the light of other evidence about the aetiology of lung cancer and chronic bronchitis and the degree and nature of the pollution of the air in retort houses, it is concluded that the excess mortality from these causes among retort house workers is occupational in origin. The risk of lung cancer is probably most marked in men who have worked in horizontal retort 
houses and may be largely confined to them. On present evidence, however, it is not possible to estimate the size of the relative risks in the different types of retort house with any confidence. Whether there is any appreciable difference in the risk of bronchitis in the different types of retort house is uncertain.

Retort house workers also had a slightly greater mortality from cancer of the bladder; in the light of other evidence, it is probable that this also reflects a small occupational hazard.

Cancer of the scrotum, long recognized as a hazard of work involving exposure to coal tar, has not yet been entirely eliminated from the industry.

Pneumoconiosis occurs occasionally as a cause of death among bricklayers who may be employed on repairing or resetting retorts; it is not a direct effect of exposure to the products of coal carbonization.

In some area Boards, the death rate from other causes among long-term employees is low compared with that recorded for all men living in the same region. The reason for this is not known.

We are most grateful to the many members of the staff of the four area Gas Boards who have voluntarily undertaken a great deal of extra work to obtain the information on which this report was based, and to Mrs. Janet Pixner of the Medical Research Council's Statistical Research Unit who followed up many of the workers who had left the industry and calculated the mortality rates.

\section{REFERENCES}

Bruusgaard, A. (1959). Opptreden av visse kreftformer blant gassverkarbeidere. T. norske Lageforen., p. 755.

Christian, H. A. (1962). J. occup. Med., 4, 133.

Cummins, C. J., Dunn, T. L., Rayner, H. E. G. and Sullivan, J. C. (1952). An Investigation into the Health of 625 Employees engaged in Gas Production in New South Wales. Division of Industrial Hygiene of the Department of Health, Sydney, N.S.W.

Daly, C. (1959). Brit. J. prev. soc. Med., 13, 14.

Doll, R. (1952). Brit. J. industr. Med., 9, 180.

, and Hill, A. B. (1964). Brit. med.J., 1, 1399 and 1460.

Fairbairn, A. S., and Reid, D. D. (1958). Brit. J. prev. soc. Med., $12,94$.

Henry, S. A. (1946). Cancer of the Scrotum in relation to Occupation. Oxford University Press, London.

-, Kennaway, E. L., and Kennaway, N. M. (1931). J. Hyg. (Lond.), 31, 125.

Kawahata, K. (1938). Gann, 32, 367.

Kennaway, E. L., and Kennaway, N. M. (1936). J. Hyg. (Lond.), 36, 236 .

Kuroda, S. (1937). Brit. J. Cancer, 1, 260.

Industr. Med. Surg., 6, 304.

-, and Kawahata, K. (1936). Z. Krebsforsch., 45, 36. er, P. J., Commins, B. T., and Waller, R. E. (1965). A study of the concentration of polycyclic aromatic hydrocarbons in

gas works' retort houses. Brit. J. industr. Med
Mantel, N. (1963). J. Amer. statist. Ass., 58, 690.

Pemberton, J., and Goldberg, C. (1954)., Brit. med. J., 2, 567.
Registrar General (1958). The Registrar General's Decennial Supplement, England and Wales, 1951. Occupational Mortality, Part II. H.M.S.O., London.

Reid, D. D., and Buck, C. (1956). Brit. J. industr. Med., 13, 265.

Stocks, P. C. (1959). Brit. med. J., 1, 74.

Sutherland, R. B. (1959). Cited by Doll, R. in Brit. J. industr. Med.,

Todd, G. L. (1957). Statistics of Smoking. Tobacco Manufacturers' Standing Committee Research Papers No. 1.
Tyrer, F. H., Gregory, J., and Carson, M. B. (1953). Trans. Ass. industr. Med. Off., 3, 246.

World Health Organization (1957). Manua! of the International Statistical Classification of Causes of Death. W.H.O., Geneva.

\section{APPENDIX}

Case 1.-Male, born 1892, entered the gas industry in 1915 and was employed as a gas stoker until 1954 when he became a coke hopper attendant. A sore appeared on the scrotum in 1955 which increased in size until July when it was treated by surgery and radiotherapy. A year later he had to stop working because of swellings in both groins; these were treated by further radiotherapy but they recurred in July, 1957, and the left leg became oedematous. Death on December 8, 1957 was attributed to ' $1(a)$ generalized carcinomatosis, $(b)$ carcinoma of scrotum'.

Case 2.-Male, born 1901. No details of employment are known until entry into the gas industry in 1924. In the industry he worked for a year as a bricklayer's labourer and for seven years as a bricklayer's improver. He became a bricklayer and retort setter in 1932 and continued in this occupation until he died on February 6, 1960. After a coroner's necropsy death was attributed to 'congestive cardiac failure due to cor pulmonale due to fibrosis of the lungs (pneumoconiosis)'.

Case 3.-Male, born 1898, served in the Army from 1915 to 1918 , when he was wounded in the left thigh and the right foot. He entered the gas industry in 1919 and worked in the retort house until becoming a bricklayer's labourer in 1922. He became a bricklayer's improver in 1924 and a bricklayer in 1935 and remained in this last occupation until his death on October 1, 1958. Necropsy showed death was due to 'bronchial pneumonia due to pneumoconiosis'.

Case 4.-Male, born 1893, started work as an apprentice bricklayer in the building industry in 1907 and continued in this occupation until joining the Army in 1914. He worked as a bricklayer with a firm manufacturing tubes from 1916 to 1920 and as a retort setter in the gas industry from 1920 to 1929 . In 1929 he returned to the building industry where he again worked as a bricklayer until 1941. After two years in Civil Defence he re-entered the gas industry in 1943 and worked as a retort setter and bricklayer until his death in 1959. In 1956 he was awarded a $10 \%$ disability pension for pneumoconiosis. Death was attributed to '(1) cor pulmonale due to pneumoconiosis and chronic bronchitis, (2) carcinoma of bronchus'.

Case 5.-Male, born 1891. No details of employment are known until his entry into the gas industry as a bricklayer's labourer in 1911. He became a bricklayer in 1930 and remained in this occupation until retiring on a pension in 1940. Death occurred on May 7, 1958 and, after a coroner's necropsy, was attributed to 'acute bronchitis due to anthracosis and silicosis'.

Case 6.-Male, born 1904, worked underground as a coal cutter for some time before entering the gas industry in 1948 as a yard labourer. From 1949 to 1953 he worked as a top man in a vertical retort house and then as a labourer on the gas mains until he died on January 30, 
1958. After a coroner's inquest death was attributed to 'cardiac failure, due to pulmonary insufficiency; pneumoconiosis (accidental)'.

Cases among Gas Board employees excluded from population under special study.

Case 7.-Male, born 1891, entered the gas industry in 1920 and was employed as a gas stoker until 1952 when his chronic bronchitis became so severe that he was found a job as a mess room attendant; he retired in July, 1956. A lesion on the scrotum was thought to be cancer in July, 1957 and was excised in September, 1957. Histological examination showed a squamous carcinoma with metastatic deposits in biopsy material from the local lymph nodes, and the inguinal glands were dissected out in the following month. In February, 1958 he was re-admitted to hospital with extensive metastases causing obstruction to the circulation of the right arm. Death on March 3, 1958 was attributed to carcinoma of the scrotum.
Necropsy showed metastases in the retroperitoneal, hilar, and cervical glands and in the liver and lungs.

Case 8.-Male, born 1886, entered the gas industry in 1906 and was employed as a tar stillman until retirement in 1954. One pitch wart was observed on the left cheek in 1943; another occurred on the left upper eyelid in 1949 and disappeared spontaneously. A small nodular lesion appeared on the scrotum in February, 1953, which had the appearance of a virus wart and was treated by scraping and cautery. Hyperkeratosis of both arms and scrotum was observed in December, 1953. A diagnosis of pitch wart on the scrotum was made in February, 1957, and the lesion was excised together with the inguinal lymph nodes. Histological examination showed keratinizing and undifferentiated squamous carcinoma in the tumour and replacing the glands. Death on July 24, 1957, was attributed to ' $1(a)$ carcinomatosis, (b) scrotal epithelioma'. 